Thomas Adams

\title{
Projeto integrado multidisciplinar para o curso de Engenharia do Petróleo da PUC-RIO
}

Trabalho de conclusão de curso apresentado à Coordenação do Curso de Especialização Tecnologias no Ensino Superior como requisito parcial para obtenção de título de Especialista em Tecnologias no Ensino Superior.

Orientador

Prof. Arthur Braga 


\section{Curso de Especialização Tecnologias no Ensino Superior}

Rio de Janeiro

Data 11 de julho de 2016

Todos os direitos reservados. É proibida a reprodução total ou parcial do trabalho sem autorização do autor, do orientador e da universidade.

\section{Perfil do aluno}

Thomas Adams

Graduou-se em Geologia pela Universidade Federal do Rio de Janeiro em 1979. Ingressou na Petrobras em 1980, onde trabalhou até 2015. Inicialmente exerceu atividades de acompanhamento geológico de poços no Rio Grande do Norte, Sergipe e Rio de Janeiro. No Rio de Janeiro trabalhou também com geoquímica no Centro de Pesquisa (CENPES) e, posteriormente, na atividade de Interpretação de Perfis.

Em 2008, participou de um curso de especialização em perfis na Universidade Petrobras e na Universidade do Texas (Austin, EUA).

Atua como professor da matéria "Fundamentos de Perfilagem" no curso de Engenharia de Petróleo da PUC-RIO desde 2009 e, eventualmente, também no IBP (Instituto Brasileiro do Petróleo). 


\section{Dedicatória}

Dedico essa monografia a Virginia, Babi e Karin. 


\section{Agradecimentos}

Agradeço à universidade PUC-RIO a oportunidade de poder cursar o curso de especialização "Tecnologias no Ensino Superior". Os conhecimentos adquiridos foram particularmente úteis para mim, que nunca tive envolvimento com o ensino acadêmico, por ser oriundo da indústria do petróleo.

Agradeço também à Petrobras, na qual trabalhei por 35 anos e na qual adquiri a quase totalidade dos meus conhecimentos nesta área.

Agradeço ao meu orientador Arthur Braga pelas valiosas sugestões.

Finalmente agradeço minha filha Babi, que foi fundamental na revisão deste texto. 


\title{
Resumo
}

O advento da cultura digital proporcionou a possibilidade e necessidade de efetuar uma série de transformações, tanto na produção do conhecimento quanto na sua transmissão, em particular nas universidades. Distintos autores, como GIBBONS, GUILES, DELORS e JOHNSON tratam desta questão e enfatizam termos como transdisciplinaridade e cultura participativa. Tradicionalmente, em sua grande maioria os cursos das universidades estão fundamentados em disciplinas, que são ministradas de uma forma individualizada, dificultando que o aluno tenha uma visão mais integrada das distintas matérias. Nesse trabalho é proposta a criação de uma nova disciplina no curso de Engenharia do Petróleo da PUC-RIO, que teria o nome provisório "Projeto integrado multidisciplinar de desenvolvimento de um campo de petróleo ". Este projeto integraria distintas disciplinas que constam da grade do curso da Engenharia do Petróleo. No projeto piloto as disciplinas contempladas seriam "Geofísica, Fundamentos de Perfilagem, Avaliação de Formação, Engenharia de Reservatório e Produção e seriam realizados pelos alunos distribuídos em grupos. Estas distintas áreas de conhecimento seriam ministradas na sequencia tradicional do desenvolvimento de um campo de petróleo e coordenadas pelos professores de cada disciplina. Desta forma pretende-se fornecer aos alunos os conceitos de transdisciplinaridade e cultura participativa, bem como uma visão mais integrada da disciplina.

\section{Palavras-chave:}

\author{
Cultura Digital, Cultura Participativa, Economia do Conhecimento, Curso \\ Engenharia do Petróleo, Ensino, Transdisciplinariedade.
}




\section{SUMÁRIO}

Introdução

Fundamentação teórica

Desenvolvimento

1. Modo de ensino no curso Engenharia do Petróleo

2. Atividade na indústria do petróleo

3. Proposta - Criação de uma nova disciplina que consta de projeto para auxiliar a preparação dos alunos para a futura vida profissional com enfoque na transdisciplinaridade e na cultura participativa

Conclusão

Referências Bibliográficas 


\section{Introdução}

A precursora da internet surgiu no final da década de 1960, projetada pelo Ministério de Defesa do governo Norte-Americano, com o objetivo de criar, em tempos de guerra fria, uma rede de comunicação alternativa em caso de um eventual ataque soviético. A internet conhecida nos dias de hoje somente teve início no começo da década de 1990, com a "World Wide Web" (Rede de Alcance Mundial). As iniciais do nome em inglês (www) ainda são usadas hoje para acessar os websites.

A internet deu início à "revolução digital", que modificou completamente a sociedade, proporcionando uma série de mudanças em todas as atividades. A comunicação entre as pessoas, por exemplo, foi totalmente modificada através do e-mail, WhatsApp, Twitter, Facebook e outras redes sociais. Especula-se que o impacto gerado pela revolução digital possa ser comparado com o da revolução industrial, ocorrida há quase 200 anos.

Infinitas atividades como, por exemplo, escolher a melhor rota no trânsito (aplicativo Waze), comprar desde passagens até geladeiras, pagar contas e consultar extratos nos bancos, podem ser realizadas em tempo real e em qualquer lugar em que exista conexão com a internet a partir de computadores, tablets ou mesmo celulares.

Algumas profissões desapareceram. Outras foram geradas. E a forma de exercer certas profissões também mudou.

Os médicos, por exemplo, relatam que atualmente muitos pacientes estão muito mais informados que antigamente sobre as suas enfermidades. $\mathrm{O}$ site de buscas "Google" fornece muitas informações sobre assuntos médicos, embora nem todas sejam necessariamente corretas. Jocosamente esta fonte de conhecimento é conhecida como "Dr. Google" (Doutor Google). Desta forma os médicos não são mais os únicos detentores do conhecimento. A sua expertise é constantemente confrontada com os conhecimentos disponíveis na internet. 
Da mesma forma, os professores são confrontados com a possibilidade de os alunos fazerem pesquisa em tempo real sobre qualquer assunto. Os professores, assim como os médicos acima citados, deixaram de ser os únicos detentores do conhecimento. Sites como Google, YouTube e a enciclopédia participativa Wikipedia, entre muitos outros, são uma fonte inesgotável de conhecimentos. É necessário ressaltar mais uma vez que a acurácia destas informações não é garantida.

A abrangência das áreas de conhecimentos disponível na internet é enorme. Mesmo áreas bastante específicas da indústria do petróleo, como a perfilagem e a petrofísica, por exemplo, estão representadas no YouTube com uma série de filmes/aulas denominada "Petrophysics for Dummies" (petrofísica para iniciantes/leigos).

Essa quebra de paradigmas sugere que o ensino precisa sofrer mudanças para se adaptar a estes novos cenários.

Os cursos de Engenharia do Petróleo são razoavelmente recentes no Brasil. O primeiro foi criado em 1993 na UENF (Universidade Estadual do Norte Fluminense). Pode ser constatado na figura abaixo que a grande maioria foi criada a partir de 2006 (CABRAL, 2012). O curso da PUC-RIO data de 2005. 


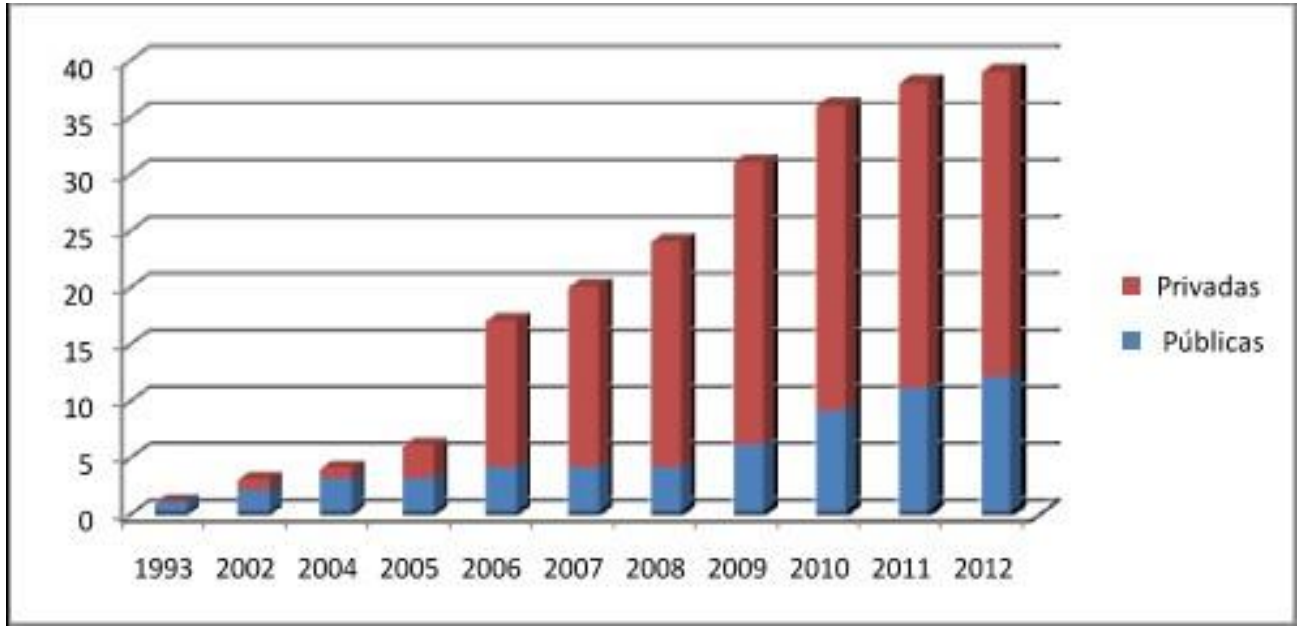

Figura 1 - Número de cursos de Engenharia do Petróleo criados por ano (CABRAL, 2012)

Estes cursos foram criados para suprir a demanda de profissionais gerada pelo crescimento da atividade da indústria petrolífera no Brasil nesta década (em particular causada pela descoberta e desenvolvimentos dos campos, alguns deles gigantes, no pós e pré-sal das Bacias de Campos e Santos).

Ao criarem estes cursos, as universidades constataram que não possuíam em seu quadro docente profissionais com o conhecimento adequado para ministrar as disciplinas mais específicas desta área de conhecimento. Desta forma, foram obrigados a buscar estes profissionais na indústria do petróleo. No caso da PUCRIO fazem parte do corpo docente alguns professores do quadro complementar (professores horistas), que exercem a atividade acadêmica paralelamente à sua atividade na indústria do petróleo.

No curso de Engenharia do Petróleo da PUC-RIO as matérias mais específicas (ciclo profissional) são ministradas a partir do quarto semestre e podem ser classificadas em três linhas básicas: Poço, Reservatório e Produção.

São relacionadas a seguir as cadeiras do ciclo profissional com suas respectivas ementas:

\section{Linha Poço:}

- Engenharia de Poço I: Operações de perfuração, métodos e equipamentos. Fluídos de perfuração e de cimentação. Perfuração no mar. 
Cálculo de vazão e queda de pressão no poço. Cálculo de pressão estática e dinâmica no fundo do poço. Limpeza de poço.

- Engenharia de Poço II: Estabilidade de poços. Projeto de poços: projeto de colunas de perfuração e de revestimento. Perfuração direcional. Complicação de poços: conceitos básicos, tipos de completação. Operações básicas.

\section{Linha Reservatório:}

- Geologia do Petróleo: A indústria do petróleo: os principais segmentos da indústria do petróleo: exploração, produção, transporte, refino e distribuição. Geologia geral: principais conceitos de geologia, geologia no tempo e espaço. Origem e constituição da terra. Principais tipos de rochas que constituem a crosta. Sedimentos, rochas sedimentares. A formação de bacias sedimentares: teoria da tectônica de placas. Derivados continentes: separação Brasil/África. Gênese e evolução das bacias sedimentares brasileiras. As bacias terrestres $\mathrm{e}$ as bacias marítimas. Sistemas petrolíferos: rochas geradoras; rochas reservatórios; rochas selantes; armadilha ou trapa, sincronismo. Geração, migração e acumulação de óleo e gás natural. Rochas geradoras: características principais. Tipos de matéria orgânica. Rochas reservatório: características principais. Aspectos texturais e composicionais. Diagênese. Porosidade e permeabilidade. Exploração e produção: fatores geológicos da exploração. Técnicas e métodos usados na exploração. Técnicas e métodos usados na produção. Delimitação e desenvolvimento de campos. Principais técnicas de estudo de rochas reservatório. Estimativas de reserva de um campo de petróleo: volume original (volume de óleo "in place" "voip"). Volume recuperável. Fator de recuperação. Produção acumulada. Fração recuperada. Reserva. Petróleo e gás no Brasil e no mundo: principais acumulações de petróleo e gás em todo o mundo.

- Química do Petróleo: Origem do petróleo: gênese do petróleo, características de geradores de querogênio. Classificação de petróleos. Composição do petróleo: distribuição de hidrocarbonetos, marcadores, compostos heteroatômicos, compostos aromáticos, asfaltenos, elementos inorgânicos. Analise dedados de testemunhos e perfis; fluidos de perfuração e complementação; acompanhamento de reservatório e de produção. Características químicas da gasolina, diesel, óleo combustível e lubrificante. Contaminação e deterioração do petróleo. Catalisadores.

- Petrofísica: Revisão de geologia do petróleo: tipos de rochas; ambientes deposicionais; geração, migração e trapeamento do petróleo; rochas reservatórios. Introdução à caracterização de reservatórios: definições; fontes de informações e integração de dados. Introdução à petrofísica: definições; utilização. Porosidade e saturação de fluidos: definições; fatores que influenciam a porosidade; laboratório: medição de porosidade e saturação de fluidos. Efeitos mecânicos sobre a rocha: tensões sobre 
rocha e fluidos; compressibilidade; laboratório: medição de compressibilidade de formação; permeabilidade absoluta: definições; experimento de Darcy; fluxo linear; fluxo radial; combinação de camadas de permeabilidade em serie e em paralelo; fatores que influenciam a permeabilidade absoluta; efeito Klinkenberg e fluxo Não Darciano; laboratório: medição de permeabilidade absoluta; propriedades elétricas: definições; lei de archie; laboratório: medição de parâmetros elétricos. Capilaridade: definições; molhabilidade; ascensão capilar; embebição e drenagem; curvas de pressão capilar; função J de Leverett; laboratório: medição de pressão capilar. Permeabilidade efetiva e relativa: definições; curvas de permeabilidade relativa; fatores que influenciam a permeabilidade efetiva e relativa; teoria de buckley \& leverett; curvas de fluxo fracionário; fluxo em regime permanente $\mathrm{x}$ regime transiente; laboratório: medição de permeabilidade efetiva e relativa; visita ao laboratório de petrofísica do Cenpes/Petrobras.

- Fundamentos de Perfilagem: Introdução à perfuração de poços de petróleo tipos de sondas rotativas: mar; terra; tipos de broca perfuração rotativa ambiente de perfilagem: tipos de fluido; tipos de invasão; alterações ocorridas ao redor do poço. Objetivos da perfilagem procedimentos antes da perfilagem tipos de perfis: poço aberto; poço revestido; perfis a cabo; perfis de $L W D$. Esquema de operação de perfilagem: cabo de perfilagem; profundidade; sondas de perfilagem; unidades de perfilagem. Conceitos: tipos de porosidade; modelo. Perfil de caliper perfil de SP perfil de GR perfis de resistividade: indução; focalizados; dielétricos. Perfis de porosidade: sônico; densidade; neutrão; ressonância magnética. Perfis de VSP e check-shot. Testadores a cabo amostradores laterais: percussivos; rotativos. Perfilagem em poços revestidos: perfis de cimentação; perfis de integridade do revestimento; perfis de determinação de contatos entre fluidos. Perfis de dipmeter e de imagem interpretação qualitativa: identificação de litologia; identificação de fluidos; identificação de fraturas. Interpretação quantitativa: conceito de resistividade; fator de formação; equações fundamentais; obtenção de $R W$; HC móvel; cálculo do volume de $\mathrm{HC}$ "in place"; correções a serem aplicadas na porosidade; equações de saturação.

- Engenharia de Reservatório I: Definição do reservatório de petróleo e gás. Classificação de reservatórios. Caracterização básica de reservatórios. Propriedades físicas: propriedades do meio poroso; propriedades físicas dos fluidos; características de pressão de reservatório; lei de Darcy, equação da difusividade. Testes de pressão, mecanismos de empuxo. Balanço de materiais. Fundamentos de transmissão de calor. Produtividade: declínio de reservatórios; propriedades PVT. Índice de produtividade. Simulação do tipo Black Oil. Balanço volumétrico. Diferenças finitas. Modelos de poço.

- Engenharia de Reservatório II: Recuperação secundária: manutenção de pressão; injeção de água; injeção de gás; eficiência de escoamento e fator 
de recuperação; métodos analíticos. Monitoramento de reservatórios: gráficos de hall e outros; testes de traçadores; perfis de produção; mapas de pressão. Recuperação avançada: métodos de recuperação avançados: desenvolvimento de reservatórios. Elementos de simulação térmica e composicional. Casos de campo.

- Avaliação de Formação: Perfilagem de cimentação e perfilagem a poço fechado, avaliação de pressão capilar e saturação, integração perfiltestemunho, net pay, reservas.

- Métodos Geofísicos: Introdução aos métodos geofísico: gravimetria; magnetometria; métodos elétricos; refração sísmica. Introdução ao método sísmico: introdução a propagação de ondas; introdução a teoria dos sinais; introdução a petrofísica; velocidades sísmicas; modelo convolucional; o pulso sísmico; propagação de ondas; resolução vertical; resolução horizontal. Noções de aquisição sísmica: fontes, receptores, instrumento de registro, posicionamento, geometria; CDP, cobertura, NMO sísmica 3D, sísmica de alta resolução, aquisições especiais. Noções de processamento sísmico: edição, deconvolução da assinatura, espalhamento geométrico, correções residuais, regularização de cobertura; atenuação de múltiplas, análise de velocidades, migração (PSTM, PSDM); velocidades de processamento, mute, empilhamento, tratamentos residuais. Noções de interpretação sísmica: apresentação, sismograma sintético, sísmica 3D, coerência; horizontalizarão, conversão tempo-profundidade, inversão, decomposição espectral. Introdução a caracterização de reservatórios: atributos sísmicos; correlação atributos x petrofísica, geoestatística, redes neurais. Noções de AVO: aproximações zoeppritz, intercept e gradiente, tipos e classes de avo, pitfalls. Introdução a sísmica de poço: check-shots, VSP, tomo grafia entre poços, perfil de reflexão, seismic while drilling. Introdução a sísmica 4D: repetibilidade, processamento 4D, sensores permanentes, exemplos reais. Tópicos especiais: introdução à sísmica multicomponente e anisotropia; noções de sísmica passiva; introdução a sea-bed logging e outros métodos elétricos.

- Mecânica de Rochas: Problemas de engenharia em meios rochosos. Propriedades-índice. Resistência de maciços rochosos, rochas intactas e descontinuidades. Deformabilidade de maciços rochosos e rochas intactas. Permeabilidade de maciços rochosos. Aplicações de mecânica das rochas: estabilidade de taludes; fundações em rochas; tensões in situ e escavações subterrâneas.

\section{Linha Produção:}

- Engenharia de Produção I: Elevação natural de petróleo. Elevação artificial de petróleo. Escoamento multifásico em tubulações. Engenharia de gás natural. Garantia de escoamento. 
- Engenharia de Produção II: Equipamentos de elevação. Separação de fases submarina. Transporte por dutos submarinos. Equipamentos submarinos.

- Sistemas Marítimos de Produção: Sistema submarino de coleta e escoamento da produção: equipamentos submarinos de coleta e escoamento; linhas rígidas e flexíveis; risers de produção; dutos de escoamento; bombas e compressores. Garantia de escoamento da produção: métodos de prevenção e remedição de depósitos e parafinas em linhas e equipamentos submarinos; controle da formação de hidratos em sistemas submarinos de produção; controle da formação de incrustações salinas. Unidades marítimas de produção: plataformas fixas características essenciais; plataformas semissubmersíveis: unidades tipo FPSO e FSO; plataformas de pernas atirantadas (TLP); plataformas tipo spar. Sistemas de amarração e ancoragem de unidades marítimas: bombeamento multifásico submarino; separação submarina de fluidos de produção; processamento primário de petróleo em sistemas offshore (separação gás liquido, tratamento de petróleo, tratamento de efluentes).

\section{Transversais:}

- Projeto de Graduação em Engenharia de Petróleo I: Desenvolvimento de um projeto de engenharia ou de um trabalho de pesquisa de caráter teórico ou experimental sob a supervisão e orientação de um professor. O projeto ou trabalho de pesquisa pode ser realizado individualmente ou em grupo, devendo ser apresentado por escrito dentro das normas estabelecidas pelo curso.

- Estágio Supervisionado em Engenharia do Petróleo: Estágio de no mínimo 160 horas em empresa preferencialmente de engenharia, ficando sua aceitação a critério da coordenação do curso.

- Análise Financeira em Engenharia do Petróleo: Desenvolvimento de um projeto de engenharia ou de um trabalho de pesquisa de caráter teórico ou experimental sob a supervisão e orientação de um professor. $\mathrm{O}$ projeto ou trabalho de pesquisa pode ser realizado individualmente ou em grupo, devendo ser apresentado por escrito dentro das normas estabelecidas pelo curso.

- Métodos Numéricos para Engenharia Mecânica: Equações diferenciais ordinárias. Problemas de valor inicial. Interpolação polinomial. Integração numérica. Estabilidade. Análise de erros. Problemas de valor de contorno. Equações diferenciais parciais. Método de volumes finitos. Técnicas para solução de sistemas algébricos. Problemas não lineares. Iteração e taxa de convergência. Método dos elementos finitos. Aplicações em problemas de engenharia mecânica. Comparações com soluções analíticas e semianalíticas. 
- Análise de Risco Ambiental: Estudo da análise de risco de segurança. Levantamento de dados. Banco de dados sobre acidentes ambientais. Formulação de hipóteses. Estimativa de frequências de probabilidades. Modelos matemáticos. Estimativa de risco. Mitigação de riscos. Estudo de casos práticos. Grandes acidentes ambientais e sua relação com análise de riscos de segurança. Casos típicos: vazamento de óleo, acidentes industriais e acidentes nucleares.

- Legislação Social: Princípios gerais de legislação trabalhistas. O contrato trabalhista. Justiça do trabalho. Organização sindical. Inspeção do trabalho. A previdência social: sínteses históricas, conceitos, aspectos técnicos e sociais, legislação.

Pode ser constatado que o curso Engenharia do Petróleo da PUC-RIO é, como a imensa maioria dos cursos universitários, estruturado no ensino de disciplinas. Cada professor ministra sua cadeira de forma isolada. Possivelmente, o fato dos professores horistas estarem menos enquadrados na vida acadêmica da universidade também pode contribuir para isso.

"Economia do Conhecimento" é um conceito que se refere à "aplicação do conhecimento de qualquer campo ou fonte, novo ou velho, como estímulo ao desenvolvimento econômico". GUILE apresenta esse conceito em "O que distingue a economia do conhecimento? Implicações para a educação" (2008), quando discute a "interdependência entre o conhecimento teórico e tácito e que isso pressupõe pedagogias que auxiliem os alunos a mediar diferentes formas de conhecimento, e não oscilar entre elas".

O relatório de J. DELORS (1996) para a Unesco sobre a educação para o século XXI propõe o conceito de quatro pilares para a educação: "Aprender a conhecer", "Aprender a fazer", "Aprender a viver juntos" e "Aprender a ser". Neste relatório são propostas pelo autor algumas alterações no modo da transmissão do conhecimento.

Adicionalmente são referenciadas tendências, apontadas pelo relatório NMC Horizon Report”" (JOHNSON, L et al. 2015), produzido pelo New Media Consortium (NMC) em conjunto com o Consortium of School Networking $(\mathrm{CoSN})$, que aceleram a adoção de tecnologias na educação básica. Apesar de o relatório estar focado na educação básica, suas premissas podem ser utilizadas também na educação superior. 
GIBBONS (Universidade de Sussex Inglaterra) publicou com outros autores em 1994 um livro com o título "The New Production of Knowledge: the Dynamics of Science and Research in Contemporary Societies", onde defende um foco maior na transdisciplinariedade e na cultura participativa.

Neste livro, GIBBONS trata da produção de conhecimento nas sociedades contemporâneas e individualiza dois modos de ensino no Ensino Superior. O Modo 1, estruturado em disciplinas, e o Modo 2, com o foco na transdisciplinaridade.

Aplicando a classificação proposta por GIBBONS pode-se afirmar que atualmente o curso Engenharia do Petróleo na PUC-RIO é estruturado principalmente no Modo 1.

Seria desejável diversificar essa tendência, oferecendo, pelo menos parcialmente, uma estrutura adicional baseada em uma cultura mais participativa (Modo 2).

Além de um curso baseado em disciplinas, poderiam ser oferecidas cadeiras com enfoque transdisciplinar. A Engenharia do Petróleo se adequa bem a este enfoque, visto que apresenta uma multidisciplinariedade elevada.

São ministradas neste curso, entre outras, cadeiras de geologia, geofísica, química e distintas engenharias (perfuração, reservatório e produção).

A dificuldade inicial é que a Engenharia do Petróleo se propõe a quantificar a natureza, o que nem sempre é fácil, visto que a natureza é heterogênea e não redundante. Uma dificuldade adicional é que os objetos de estudo, os reservatórios de petróleo, se situam a elevadas profundidades na subsuperficie, sendo assim inacessíveis, o que implica na necessidade de serem avaliados de forma remota e indireta.

Para implementar uma cultura mais participativa e transdisciplinar na Engenharia do Petróleo da PUC-RIO, sugere-se a criação de uma cadeira que conste de um projeto multidisciplinar visando à integração de distintas áreas de 
conhecimento. Esse projeto seguiria o cronograma do desenvolvimento de um campo de petróleo e os alunos trabalhariam em grupos.

Seria composto por diversas etapas, coordenadas por diferentes professores. Um projeto piloto, inicialmente, teria etapas dedicadas a distintas áreas de interesse, tais como Geofísica, Fundamentos de Perfilagem, Avaliação de Formação, Engenharia de Reservatório e Produção. Seriam utilizados os dados liberados pela ANP de um campo de petróleo.

A execução de projeto com estas características (grupos de alunos e um grupo de professores) é possibilitada pela disponibilização das ferramentas de comunicação da cultura digital.

O produto final do projeto seria um projeto de produção para o campo de petróleo. Uma fase muito importante seria comparar o projeto gerado pelos alunos com aquele implementado de fato quando o campo foi desenvolvido. 


\section{Fundamentação Teórica}

Vários autores têm proposto que o ensino no século XXI deveria ter o seu enfoque alterado. O ensino formal não deve constar apenas da "tradicional" aquisição de conhecimento, da forma que é habitualmente ministrada. Os alunos devem ser preparados também para estarem aptos a trabalhar com cultura participativa e em equipes transdisciplinares.

DAVID GUILE escreveu em 2008 um abrangente artigo chamado " $O$ que distingue a economia do conhecimento? Implicações para a educação”. Serão apresentados a seguir uma série de conceitos apresentados por ele. Afirma que o objetivo deste artigo é compensar a insuficiência da teorização a respeito da economia do conhecimento por parte dos sociólogos e identificar as implicações da análise aqui desenvolvida para a educação".

GUILE referencia o termo "economia do conhecimento", que foi cunhado por DRUCKER (1969) para se referir "a aplicação do conhecimento de qualquer campo ou fonte, novo ou velho, como estímulo ao desenvolvimento econômico". BELL (1974) afirma que "alguma forma de conhecimento sempre foi fundamental para o funcionamento de qualquer sociedade". Segundo o mesmo autor (1979) o conhecimento teórico teria adquirido esse novo papel porque a mudança de uma economia de produção para uma economia de serviços significava que: "quando o conhecimento se torna envolvido de alguma forma sistemática na transformação aplicada dos recursos, então pode-se dizer que o conhecimento, não o trabalho, é a fonte de valor".

Essa definição faz sentido quando se compara o estágio de desenvolvimento da Coréia com o do Brasil. Na década de 70, a Coréia apresentava um estágio de desenvolvimento inferior ao do Brasil. Graças a uma política mais agressiva de investimento em educação, aquele país hoje se situa em um estágio superior de desenvolvimento em relação ao nosso.

Quase vintes anos mais tarde, CASTELLS (2000) escreveu uma trilogia chamada "The information age: economy, society and culture", na qual 
desenvolve as ideias de BELL, enfatizando, porém, o papel da Tecnologia da Informação e Comunicação" (TIC).

Segundo GUILE, BELL e CASTELLS aceitam que o conhecimento tem importância fundamental para o desenvolvimento econômico nas sociedades industriais avançadas. BELL, porém concentrou-se na aplicação da ciência como estimulo à prosperidade econômica, enquanto CASTELLS acrescentou a aplicação tecnológica na forma de TIC e com a aplicação dos dados gerados pela TIC.

GUILE afirma que BELL e CASTELLS concebiam a ciência como a principal fonte do conhecimento. Na segunda metade do século passado alguns cientistas sociais consideram-na em termos mais modestos e instrumentais (OSBORNE, 1998).

GUILE menciona que a relação entre ciência e sociedade está no cerne das colocações de diversos autores, citando ETZKOWITZ e LEYDESDORFF (1997), os quais afirmam: "o surgimento da tripla hélice entre as universidades, a indústria e o Estado que, de maneira significativa, ampliou a gama de grupos de interesse preocupados com a produção de conhecimento nas sociedades industriais avançadas”.

GUILES afirma que "a manifestação dessa nova relação entre ciência e sociedade tem sido o debate em outras áreas das ciências sociais - por exemplo, os estudos sobre gestão e políticas científicas - sobre a emergência de um novo modo de produção de conhecimento, uma nova concepção de conhecimento e sua contribuição para a sociedade/economia do conhecimento".

Em 1994, GIBBONS et al. publicaram o livro "The New Production of Knowledge: the Dynamics of Science and Research in Contemporary Societies", no qual identificam as mudanças nos modos de produção de conhecimento nas sociedades modernas. O escopo do livro é amplo, abrangendo tanto as ciências sociais e humanas, quanto as áreas científicas e tecnológicas. 
GIBBONS et al. constatam que a forma com que o conhecimento é produzido e transmitido está mudando. Estabeleceram dois modos distintos da estrutura das ciências e do ensino nas instituições de ensino superior.

O modo 1 é baseado em estruturas com disciplinas. Isso seria a forma tradicional de ensino lecionado nas universidades.

Já o modo 2 apresenta o foco na transdisciplinaridade. Além disso, a produção do conhecimento é socialmente distribuída. Nesse contexto, as relações são colaborativas, o que é possibilitado pelas modernas formas de comunicação disponibilizadas pela cultura digital.

A natureza dessa transformação é tratada em capítulos separados: ciências (capítulo 1), tecnologia (capítulo 2) e ciências humanas (capítulo 4). Já as mudanças sociais são tratadas em todo o texto.

Abaixo são listadas diferenças entre os dois modos apontadas pelos autores.

- No Modo 1 os problemas são colocados em um contexto, frequentemente acadêmico e abstrato, formulado pelos interesses de uma comunidade específica. Já no modo 2, os problemas geralmente são mais práticos e sua solução impacta uma parte maior da sociedade.

- O Modo 1 é disciplinar enquanto o Modo 2 é transdisciplinar

- O Modo 1 é mais homogêneo e hierárquico, enquanto o Modo 2 é mais heterogêneo e não hierárquico.

- Em geral, o Modo 2 está mais inserido na sociedade e a sua comunidade é menos perene e mais heterogênea, lidando com problemas mais específicos que os do Modo 1.

- O fato de a comunidade do Modo 2 ser mais heterogênea pode sugerir que as soluções obtidas sejam mais robustas. 
- Segundo os autores, o Modo 2 de conhecimento "abrange os conhecimentos heterogêneos e transdisciplinares criados em contextos de aplicação" e "caracterizados por um fluxo constante, num ir e vir entre o fundamental e o aplicado, entre o teórico e o prático" (p.18).

Para GIBBONS et al., ocorre uma contínua diminuição do isolamento social da ciência, que constitui prova incontroversa de uma tendência que dará continuidade a uma demanda crescente pelo Modo 2. Esta demanda não se daria apenas nos campos científicos, mas também, de forma mais ampla, na sociedade.

Além disso, a aceitação geral de uma concepção do conhecimento mais pluralista também alimentará, de acordo com GIBBONS et al., uma demanda por novos padrões em relação aos quais o conhecimento poderá ser avaliado; esse desenvolvimento consolidará a mudança em direção a uma "sociedade Modo 2".

No final do seu artigo GUILE trata das implicações educacionais do "Conhecimento" sobre a Economia do Conhecimento. O conceito de "Economia do Conhecimento" foi empregado em dois sentidos: como uma visão de atividade econômica futura e como embasamento para políticas de aprendizagem ao longo da vida.

GUILE cita o então secretário de Estado para Educação do Reino Unido DAVID BLUNKETT: “Aprender é a resposta para a prosperidade - para cada um de nós individualmente e para a nação como um todo. Os investimentos no capital humano serão a base para o sucesso na economia global baseada no conhecimento do século $21 "$.

Semelhantemente o "Memorando sobre Aprendizagem ao Longo da Vida" da União Europeia, declara que "o objetivo dos formuladores de políticas educacionais da UE deverá ser o de identificar: "estratégias coerentes e medidas práticas com a finalidade de estimular a aprendizagem ao longo da vida para 
todos, de modo a ajudar a Europa a tornar-se a sociedade baseada no conhecimento mais dinâmica e competitiva do mundo".

Segundo GUILE existem, porém, diferentes concepções sobre a transmissão do conhecimento: a "tradicional", a "utilitária" e a "pós-moderna".

A concepção "tradicional" endossa a existência de um determinado “corpus" de conhecimento, que deve ser transmitida pelas universidades.

A concepção "utilitária" concebe o conhecimento como um meio para um fim. O currículo universitário seria uma contribuição à realização da "forma da sociedade" desejada pelos formuladores de políticos, ao passo que a pesquisa deveria amparar a industrialização.

$\mathrm{Na}$ ótica "pós-moderna" qualquer currículo fundamentado nas concepções "tradicional" e "utilitária" é baseada em pressupostos arbitrários sobre conhecimento e cultura.

Essa diversidade de conceitos apresentada acima acaba sendo responsável por distintas formas de políticas de educação superior.

Uma corrente tradicional defende a ideia de que todo conhecimento baseia-se em formas de generalização (representações abstratas do mundo), radicadas em tradições disciplinares ou multidisciplinares bem estabelecidas, a fim de que possam usar o conhecimento em modos tradicionalmente esperados como, por exemplo, em trabalhos escritos.

A visão oposta à esta supõe que "qualquer forma de conhecimento seja maleável, desde que os alunos tenham desenvolvido as principais competências necessárias para aplicá-las em diferentes contextos. Assim, atualmente se espera que as universidades ajudem os alunos a adquirir conhecimentos disciplinares, assim como os capacitem a adquirir competências descontextualizadas (isto é, competências centrais) em situações com contextos específicos (isto é, palestras, laboratórios, estágios) (GUILE, 2001)". 
GUILE afirma que ocorre um sério dilema pedagógico sobre concentrar ou dividir a atenção: "Os alunos oscilam entre ter de concentrar sua atenção em especificações de programas claramente definidas com base nas disciplinas do conhecimento, ou dividir sua atenção em inúmeras aptidões, a fim de se envolver e responder às formas heterogêneas de conhecimento, atualmente aceitas no ensino superior".

O autor também afirma: "a economia do conhecimento tem explicitado a já antiga interdependência entre o conhecimento teórico e tácito e isso pressupõe pedagogias que auxiliem os alunos a mediar diferentes formas de conhecimento, e não oscilar entre elas" (p.633).

J. DELORS (1996) publicou um relatório para a Unesco sobre a educação para o século XXI no qual são propostos quatro pilares para a educação ao longo de toda a vida: “Aprender a conhecer", "Aprender a fazer", "Aprender a viver juntos" e "Aprender a ser". .

Sucintamente o pilar "Aprender a Conhecer" consta na combinação de uma cultura geral vasta com a possibilidade de trabalhar em profundidade um reduzido número de matérias. O segundo pilar "Aprender a fazer" trata do aprendizado não só da qualificação profissional (que já é executada pelas universidades), mas também de uma competência que torne a pessoa apta a enfrentar numerosas situações e a trabalhar em equipe. Propõe oferecer um aprendizado alternando o ensino "tradicional" com situações que retratam situações do trabalho. O terceiro pilar é o "Aprender a viver juntos", no qual a proposta é a compreensão do outro e a percepção das interdependências realizando projetos comuns e preparando-se para gerir conflitos, com ênfase nos valores do pluralismo, da compreensão mútua e da paz. O quarto e último pilar proposto é o "Aprender a ser", que visa preparar pessoas com cada vez mais maior capacidade de autonomia, discernimento e responsabilidade pessoal. A ênfase é não negligenciar na educação nenhuma das potencialidades de cada indivíduo: memória, raciocínio, sentido estético, capacidades físicas, aptidão para comunicar-se. 
O relatório de J. DOLORS sustenta que os sistemas educativos formais atuais tendem a privilegiar o acesso ao conhecimento, em detrimento de outras formas de aprendizagem e que importa conceber a educação como um todo. "Esta perspectiva deve, no futuro, inspirar e orientar as reformas educativas, tanto em nível da elaboração de programas como da definição de novas políticas pedagógicas".

O New Media Consortium (NMC) em conjunto com o Consortium of School Networking (CoSN) produziu um relatório denominado "NMC Horizon Report" (JOHNSON, L et al. 2015). Este trabalho visa a responder algumas perguntas que abrangem um horizonte dos próximos cinco anos na educação básica. Apesar de o relatório estar focado na educação básica, suas premissas podem ser utilizadas na educação como um todo.

O relatório se propõe a responder algumas perguntas, tais como:

1. Qual das principais tecnologias catalogadas na listagem NMC Horizon Project será mais importante para o ensino nos próximos cinco anos: a aprendizagem ou a investigação criativa na educação básica?

2. Que "tecnologias-chave" estão faltando em nossa lista? Considere estas perguntas relacionadas:

3. O que você lista entre as tecnologias estabelecidas que algumas escolas estão usando hoje, que, sem dúvida, todas as escolas devem usar de forma ampla para apoiar ou melhorar o ensino: a aprendizagem ou a investigação criativa?

4. Quais tecnologias que têm uma base de usuários sólida em consumo, entretenimento ou outras indústrias devem as escolas ativamente procurar aplicar?

5. Quais são as principais tecnologias emergentes que vão se desenvolver a tal ponto que as escolas devam começar a tomar conhecimento durante os próximos quatro a cinco anos? 
6. Quais as "tendências-chave" que você espera para acelerar a absorção de tecnologia educacional na educação básica?

7. O que você vê como desafios significativos que impedem a absorção de tecnologia educacional na educação básica durante os próximos cinco anos?

Estas questões em relação à adoção de tecnologia e a transformar o ensino e a aprendizagem dirigiram a pesquisa colaborativa e discussão de um corpo de 56 especialistas.

No relatório são enumeradas uma série de tendências que aceleram a adoção de tecnologias na educação básica, que são classificadas conforme o seu impacto e tempo de implementação.

Abaixo são reproduzidas duas destas tendências

- Em todo o mundo, as escolas estão mudando os papéis dos estudantes de consumidores passivos de conteúdos $e$ conhecimentos para criadores. Ao integrar as ferramentas digitais nas aulas, os alunos estão produzindo meios de comunicação e protótipos com mais fluidez, levando a um maior compromisso com a aprendizagem

- O aumento do uso de abordagens de aprendizagem colaborativa que remete a estudantes ou professores que trabalham juntos por meio de atividades em pares ou em grupo, baseia-se na perspectiva de que a aprendizagem é uma construção social. A abordagem envolve atividades que geralmente são focadas em torno de quatro princípios: colocar o aluno no centro, enfatizar a interação e ação, trabalhar em grupos e desenvolver soluções para os problemas do mundo real. Modelos de aprendizagem colaborativa se revelam bem-sucedidas por melhorar o engajamento e desempenho dos alunos, especialmente com estudantes desfavorecidos. Os professores também se beneficiam através de grupos de pares ao 
passo que se envolvem com o desenvolvimento profissional $e$ oportunidades de ensino interdisciplinares. Uma dimensão adicional a essa tendência é um foco crescente na colaboração global online, em que as ferramentas digitais contemporâneas são usadas para interagir com outros ao redor do mundo, dando suporte aos objetivos curriculares e à compreensão intercultural. Através da proliferação de ferramentas online e móveis, está cada vez mais simples para os estudantes aprimorar em suas habilidades de colaboração a qualquer hora e em qualquer lugar.

Pode-se concluir que estes diversos autores; GUILES, GUIBBONS, DELORS, entre outros; apontam para o fato de que estamos em um momento de transição. A forma da transmissão do conhecimento está mudando para um enfoque mais colaborativo e transdisciplinar. Trabalhos em grupo são incentivados. Cabe às universidades se prepararem para essa grande e importante tarefa. 


\section{Desenvolvimento}

\section{1) Modo de ensino no curso Engenharia do Petróleo}

Em geral, o ensino praticado no curso de Engenharia do Petróleo da PUCRIO está estruturado no ensino de disciplinas, que são ministradas pelos professores de uma forma individualizada e autônoma. Assim sendo, se encaixa mais no Modo 1 de aprendizado apresentado por GIBBONS et al,1994 em sua classificação e na concepção tradicional de GUILE (2008).

Como cada matéria é ministrada de forma individual, cabe ao aluno juntar todo esse conhecimento adquirido em partes e montar o seu próprio "quebracabeça", tendo desta forma a sua percepção do "conjunto da obra".

É conveniente ressaltar que uma parte dos professores que ensinam na "Engenharia do Petróleo" são profissionais que atuam, ou atuaram, na indústria do petróleo. Isso talvez agregue a este departamento um perfil distinto, se comparados com demais departamentos da Universidade. Por trabalharem na indústria do petróleo possuem uma boa vivência no trabalho multidisciplinar.

Paradoxalmente, atuam na vida acadêmica de forma mais individualizada. Contribui para isso o fato de serem professores horistas que não estão encaixados na rotina da vida acadêmica.

Seria positivo oferecer, pelo menos parcialmente, uma abordagem mais colaborativa e transdisciplinar no aprendizado. Essa abordagem se encaixaria no modo 2 de GIBBONS e no conceito utilitário e pós-moderno de GUILE.

Se propõe a criação de uma matéria que conste de um projeto que simule o desenvolvimento de um campo de petróleo. Este seria realizado por alguns grupos de alunos, o que incentivaria a abordagem colaborativa. O escopo deste projeto seria composto por distintas matérias, o que reforçaria a abordagem transdisciplinar.

Os alunos pertencem, em sua grande maioria, à chamada "geração Y", naturalmente encaixada na Cultura Digital. 
$\mathrm{O}$ advento da cultura digital permitiu ao ensino ficar mais alinhado no Modo 2 de GIBBONS. A Cultura Digital permite justamente o ir e vir entre distintas fontes de referência. A grande vantagem do hipertexto, por exemplo, é justamente permitir "navegar" com facilidade e rapidez por diversas áreas de conhecimento.

As atuais possibilidades de comunicação oferecidas pela cultural digital, como e-mails e WhatsApp, facilitam sobremaneira a execução de um projeto com estas características. Da mesma forma, a possibilidade de salvar e acessar o projeto realizado por um grupo de alunos na "nuvem" facilita a execução do mesmo.

\section{2) Atividade na indústria do petróleo}

A indústria do petróleo é uma área de interpendência por excelência. $\mathrm{Na}$ área de Exploração e Produção, por exemplo, trabalham profissionais das mais diversas áreas, como engenheiros das mais distintas especialidades, geofísicos, geólogos, químicos, técnicos de perfuração e logística, economistas, administradores, etc.

Muito frequentemente, estes profissionais participam de reuniões onde vários "pontos de vista" precisam ser contemplados na programação das operações e na resolução de problemas. Reuniões de profissionais, de qualquer número, são a rotina.

Com o advento da cultura digital, estas reuniões frequentemente são realizadas através de teleconferência, onde os participantes participam da reunião em seus locais de trabalho, economizando o tempo do deslocamento.

É fundamental que os alunos da Engenharia do Petróleo estejam adaptados para esse aspecto multilateral da atividade. Apesar de serem engenheiros, precisam compreender a forma de pensar e agir dos demais especialistas, como por exemplo, dos geólogos. Estes profissionais passam por uma intensa interação, particularmente nos estudos dos reservatórios. 
GUIBONS menciona também o mundo teórico versus o prático. $\mathrm{O}$ universo da Geologia vive essa situação no seu dia a dia. Modelos teóricos são propostos para a natureza, mas a realidade raramente se apresenta daquela forma. Cabe aos profissionais desta indústria serem ótimos observadores, mas também terem a capacidade de pensar "fora da caixa" e serem humildes, para se conformar com o fato que existem diversas respostas para cada contexto estudado. É importante que esta realidade também seja assimilada pelos estudantes da Engenharia do Petróleo.

3) Proposta - Criação de uma nova disciplina que consta de projeto para auxiliar a preparação dos alunos para a futura vida profissional com enfoque na transdisciplinaridade e na cultura participativa

\section{Problema:}

O curso de Engenharia do Petróleo da PUC-Rio é fundamentado no ensino de disciplinas, que são ministradas de forma individualizada. O trabalho em equipe e a transdisciplinariedade poderiam, e deveriam ser mais estimulados.

Os alunos frequentemente não têm uma visão holística do curso.

\section{Meta:}

Inserir no ensino do curso de engenharia do petróleo, pelo menos parcialmente, uma abordagem mais participativa e transdisciplinar.

Incentivar a formação de profissionais com a mente aberta, aptos para transitarem em áreas distintas.

Criação de uma disciplina onde os alunos formariam times de trabalho para executar um projeto com focos em distintas disciplinas e orientados por professores com distintas especializações. Esse projeto seria executado na mesma cronologia que um projeto de exploração e desenvolvimento de um campo de petróleo. 
Com este passo se deseja incentivar o trabalho em grupo dos alunos, proporcionando uma cultura participativa e transdisciplinar, preparando os alunos para sua atuação nas companhias de petróleo, que são multidisciplinares por excelência.

Nome provisório da disciplina: "Projeto integrado multidisciplinar de desenvolvimento de um campo de petróleo".

\section{Detalhamento:}

Em um projeto piloto poderiam ser inicialmente contempladas as áreas de Geofísica, Análise de Perfis, Avaliação de Formação, Engenharia de Reservatório e Engenharia de Produção, que constam da grade do curso da Engenharia do Petróleo e que seriam realizados em sequência, sempre coordenados pelo professor de cada disciplina.

Esta disciplina teria evidentemente como pré-requisito os alunos terem cursado as respectivas disciplinas.

Posteriormente a quantidade de áreas contempladas poderia ser alterada. Caso necessário, a disciplina poderia ser desmembrada em partes (I, II etc.)

Poderiam ser utilizados dados liberados pela ANP (Agência Nacional de Petróleo) de determinado campo de petróleo, como por exemplo o Campo de Namorado, da Bacia de Campos (RJ).

A ideia seria simular as diversas etapas do desenvolvimento de um campo de petróleo.

A primeira etapa se daria abrangendo a área de geofísica, que na PUC-RIO é tratada na cadeira de "Métodos Geofísicos". Com a coordenação do professor da disciplina, os alunos analisariam as seções sísmicas disponibilizadas e escolheriam a posição ideal para a perfuração dos poços (comparando com os poços de fato perfurados). Os resultados obtidos seriam comparados com as medidas que foram de fato implementadas naquele campo de petróleo. 
Em seguida, o professor da cadeira de "Fundamentos de Perfilagem" coordenaria a interpretação dos perfis pelos alunos de alguns poços selecionados, determinando tanto topo e base dos reservatórios, como as profundidades dos contatos entre os fluídos (gás/óleo/água). Além disso calcular parâmetros médios do reservatório como argilosidade, porosidade e saturação de fluídos.

A seguir, os professores das cadeiras de "Avaliação de Formação" e "Engenharia de Reservatório I e II" poderiam coordenar a interpretação dos testes de formação e demais dados obtidos no esforço exploratório daquele campo, com o intuito de caracterizar aquele reservatório da melhor forma possível.

Um dos professores da "Engenharia de Produção I e II" coordenaria a utilização destes dados pelos alunos para modelar aquele reservatório, efetuando diferentes simulações para propor o melhor modelo de explotação.

O produto final seria um modelo verossímil de exploração e produção daquele campo. Esse modelo seria comparado com aquele gerado no desenvolvimento daquele campo.

Para coordenar uma matéria com um coordenador, vários professores e vários alunos distribuídos em grupos é absolutamente fundamental a utilização de tecnologias disponibilizadas pela internet, como grupos de WhatsApp entre os professores e a coordenação, bem como entre os professores e alunos e também, evidentemente, entre os participantes de cada grupo de alunos.

Etapas Necessárias para a possível implantação do projeto

- Reunião com a coordenação do curso da Engenharia do Petróleo para avaliar as potencialidades e demandas deste projeto. Além disso, compor lista com os nomes dos professores que seriam convidados para participar do projeto piloto.

- Reunião com os professores convidados das distintas disciplinas para avaliar a viabilidade da realização deste projeto, bem como as demandas de tempo e recursos estimadas por cada um. 
- Se o projeto fosse considerado apto para prosseguir, consolidar medidas necessária com as demandas elencadas na etapa anterior

- Nomeação de um coordenador da matéria

- Uma vez implementada, fazer a divulgação da matéria com os alunos

- Acompanhar este projeto piloto, para observar acertos e erros.

- Ao final do curso fazer uma pesquisa com os alunos e professores participantes

- Consolidar qualidades e possibilidades de melhorias

- Implementar mudanças 


\section{Conclusão}

A criação da internet no início da década de 1990 contribuiu em muito para a "revolução digital", que modificou completamente a sociedade, proporcionando uma série de mudanças em todas as atividades

A cultura digital proporcionou uma quebra de paradigmas na educação. Cada vez menos os professores são as únicas fontes do conhecimento. Os alunos podem consultar em tempo real diversos sites na internet, como Google, "YouTube" e a enciclopédia participativa Wikipedia, entre muitos outros. Isso sugere que o ensino precisa efetuar uma série de transformações para se adaptar a estes novos cenários.

Tem sido constatada por diferentes autores a necessidade de alterar o enfoque do ensino no século XXI. O advento da cultura digital proporcionou a possibilidade de efetuar uma série de transformações, tanto na produção do conhecimento quanto na sua transmissão.

O ensino formal não deve constar apenas da "tradicional" aquisição de conhecimento, da forma que é habitualmente ministrada. Os alunos devem ser preparados também para estarem aptos a trabalhar em equipes transdisciplinares.

GUILE (1999) discute de forma abrangente o conceito da "Economia do Conhecimento", apresentando o ponto de vista de diversos autores, como DRUCKER, BELL, CASTELLS, GIBBONS, ETZKOWITZ e LEYDESDORFF. Discute também a implicação da "Economia do Conhecimento" para a educação superior. Apresenta três concepções distintas do conhecimento, que estão incorporadas na política educacional para o ensino superior. A "tradicional", a "utilitária" e a "pós-moderna". Apresenta um sério dilema pedagógico que afeta os alunos. Eles ficam divididos em "concentrar a sua atenção" em programas claramente definidos com base nas disciplinas do conhecimento ou "dividir sua atenção" em inúmeras aptidões a fim de se envolver e responder às formas heterogêneas de conhecimento atualmente aceitas no ensino superior. 
GIBBONS et al,1994 constatam que a forma com que o conhecimento é produzido e transmitido está mudando. Estabeleceram dois modos distintos da estrutura das ciências e do ensino nas instituições de ensino superior. O modo 1 é baseado em estruturas com disciplinas. Isso seria a forma tradicional de ensino lecionado nas universidades. Já o modo 2 apresenta $o$ foco na transdisciplinaridade e a produção do conhecimento é socialmente distribuída. Nesse contexto, as relações são colaborativas, o que é possibilitado pelas modernas formas de comunicação disponibilizadas pela internet.

O relatório de J. DELORS (1996) para a Unesco sobre a educação para o século XXI propõe quatro pilares para a educação ao longo de toda a vida: “Aprender a conhecer", “Aprender a fazer", “Aprender a viver juntos" e “Aprender a ser". Um dos tópicos defende que o aprendizado não deveria constar só da qualificação profissional, mas também de uma competência que torne a pessoa apta a enfrentar numerosas situações e a trabalhar em equipe. Propõe oferecer um aprendizado alternando o ensino "tradicional" com situações que retratam situações do trabalho. Defende também que os alunos deveriam ser preparados para perceber a compreensão do outro (ser humano) e também a percepção das interdependências - realizando projetos comuns e preparando-se para gerir conflitos, com ênfase nos valores do pluralismo, da compreensão mútua e da paz. Cita a necessidade de preparar pessoas com cada vez mais maior capacidade de autonomia, discernimento e responsabilidade pessoal

O relatório "NMC Horizon Report” (JOHNSON, L et al. 2015) relata que, no mundo, as escolas estão mudando os papéis dos estudantes de consumidores passivos de conteúdos e conhecimentos para criadores. Ao integrar as ferramentas digitais nas aulas, os alunos estão produzindo meios de comunicação e protótipos com mais fluidez, levando a um maior compromisso com a aprendizagem.

Pode ser concluído que estamos em um momento de transição. A forma da transmissão do conhecimento está mudando para um enfoque mais colaborativo e transdisciplinar, onde trabalhos em grupo são incentivados.

As universidades devem se preparar para atuar neste processo. 
O ensino praticado no curso de Engenharia do Petróleo da PUC-RIO está estruturado no ensino de disciplinas, que são ministradas pelos professores de uma forma individualizada.

Seria positivo retratar uma situação de trabalho, e inserir, pelo menos parcialmente, uma abordagem mais participativa e transdisciplinar,

Propõe-se a criação de uma matéria, com o nome provisório de "Projeto integrado multidisciplinar de desenvolvimento de um campo de petróleo", onde os alunos reunidos em grupos executariam um projeto com focos em distintas matérias e orientados por professores com distintas especializações. As etapas desse projeto seriam executadas na mesma cronologia que um projeto de exploração e desenvolvimento de um campo de petróleo.

As matérias contempladas no projeto piloto poderiam inicialmente ser: Geofísica, Análise de Perfis, Avaliação de Formação, Engenharia de Reservatório e Engenharia de Produção. O produto final seria um modelo de exploração e produção daquele campo. Este modelo gerado pelos alunos seria comparado com aquele efetivamente implementado durante o desenvolvimento daquele campo.

A meta seria estimular entre os alunos a cultura participativa e um melhor entendimento da transdisciplinaridade, além de permitir uma visão mais holística da engenharia e geologia do petróleo.

A cultura participativa e a transdisciplinariedade são elementos particularmente importantes e rotineiros na rotina do trabalho da indústria petrolífera. Profissionais das mais diferentes especializações trabalham rotineiramente em conjunto para desenvolver projetos e acompanhar o seu desenvolvimento. Existe uma profunda interdependência entre as mais distintas áreas de conhecimento e especializações. Quanto mais integrada for esta equipe multidisciplinar, mais otimizado será o produto deste trabalho.

Esta realidade da indústria do petróleo é mais um indicativo positivo para implantar estes conceitos no curso de Engenharia do Petróleo da PUC-RIO. Os alunos, desta forma, ao ingressarem na vida profissional, já estariam mais 
preparados e ambientados neste tipo de cultura participativa e ambiente multidisciplinar. 


\section{Referências Bibliográficas}

CABRAL, C. Um panorama dos cursos de engenharia de petróleo no Brasil. Congresso Brasileiro de Educação em Engenharia, 2012.

GUILE, D. O que distingue a economia do conhecimento? Implicações para a educação. Cad. Pesqui. [online]. 2008, vol.38, n.135, pp.611-636. .

DELORS, J., et al. (1996). O Relatório Delors: Relatório para a Unesco da Comissão Internacional sobre Educação para o Século XXI. Publicado em forma de livro no Brasil, com o título Educação: Um Tesouro a Descobrir (UNESCO, MEC, Cortez Editora, São Paulo, 1999).

JOHNSON, L., et al. (2015). NMC Horizon Report: Edição Educação Básica 2015. Austin, Texas: The New Media Consortium.

GIBBONS, M. et al. The New Production of Knowledge: the Dynamics of Science and Research in Contemporary Societies. London Sage Publications, 1994. 